OPEN ACCESS

Edited by:

Youhui Lin,

Xiamen University, China

Reviewed by:

Mingzai Wu,

Anhui University, China

Khaled Mohammad Saoud,

Virginia Commonwealth University

School of the Arts, Qatar

*Correspondence:

Yao Chen

chenyao@nwpu.edu.cn

†These authors have contributed equally to this work

Specialty section:

This article was submitted to Nanoscience,

a section of the journal

Frontiers in Chemistry

Received: 23 May 2020 Accepted: 24 August 2020 Published: 21 October 2020

Citation:

Yang Y, Li T, Qin Y, Zhang L and Chen $Y$ (2020) Construct of Carbon Nanotube-Supported $\mathrm{Fe}_{2} \mathrm{O}_{3} \mathrm{Hybrid}$

Nanozyme by Atomic Layer

Deposition for Highly Efficient

Dopamine Sensing.

Front. Chem. 8:564968

doi: 10.3389/fchem.2020.564968

\section{Construct of Carbon} Nanotube-Supported $\mathrm{Fe}_{2} \mathrm{O}_{3}$ Hybrid Nanozyme by Atomic Layer Deposition for Highly Efficient Dopamine Sensing

\author{
Yingchun Yang ${ }^{\dagger}$, Tao $\mathrm{Li}^{\dagger}$, Yong Qin, Lianbing Zhang and Yao Chen* \\ School of Life Sciences, Northwestern Polytechnical University, Xi'an, China
}

The $\mathrm{Fe}_{2} \mathrm{O}_{3}$ nanozyme has been identified as the most promising alternative for the $\mathrm{Fe}_{3} \mathrm{O}_{4}$ nanozyme due to its relatively low toxic risk and good chemical stability. However, its enzyme-like activity is relatively low enough to meet specific application requirements. Furthermore, previous synthesis approaches have difficulties in fabricating ultra-small $\mathrm{Fe}_{2} \mathrm{O}_{3}$ nanoparticles with tunable size and suffer from agglomeration problems. In this study, atomic layer deposition (ALD) was used to deposit $\mathrm{Fe}_{2} \mathrm{O}_{3}$ on surfaces of carbon nanotubes to form hybrid nanozymes $\left(\mathrm{Fe}_{2} \mathrm{O}_{3} / \mathrm{CNTS}\right)$. ALD enables the preparation of ultrafine $\mathrm{Fe}_{2} \mathrm{O}_{3}$ nanoparticles with precise size control $<1 \mathrm{~nm}$, while CNTs could be served as promising support for good dispersibility and as an effective activity activator. Hence, the formed $\mathrm{Fe}_{2} \mathrm{O}_{3} / \mathrm{CNTS}$ exhibit excellent peroxidase-like activity with a specific peroxidase activity of $24.5 \mathrm{U} \mathrm{mg}^{-1}$. A colorimetric method for sensing dopamine (DA) was established and presented good sensitivity with a limit of detection (LOD) as low as $0.11 \mu \mathrm{M}$. These results demonstrated that, in virtue of meticulous engineering methods like ALD, carbon nanomaterial-based hybrids can be developed as talented enzyme mimetic, thus paving a way for nanozyme design with desired activity and broadening their applications in biosensing and other fields.

Keywords: atomic layer deposition, hybrid nanozymes, ultrafine $\mathrm{Fe}_{2} \mathrm{O}_{3}$ nanoparticles, peroxidase activity, biosensing

\section{INTRODUCTION}

It is well-known that nanozymes have been developed as the most promising alternative for natural enzymes, owing to their good stability, simple and large-scale preparation, and cost effectiveness (Gao et al., 2007; Lin et al., 2014; Wang et al., 2019). In the past 10 years, over 300 kinds of nanomaterials, including metals, metal oxides, and carbon nanomaterials, have been demonstrated to mimic the activities of oxidase, peroxidase, catalase, and superoxide dismutase, which connects an important bridge between nanotechnology and biological science (Natalio et al., 2012; Wei and Wang, 2013; Liu and Liu, 2017; Li et al., 2018; Wu et al., 2019).

As the most studied nanozymes, iron oxide nanozymes (IONzymes) have attracted great interest since the first exciting discovery that ferromagnetic oxide possesses an intrinsic peroxidase activity (Gao et al., 2007), and they show great application potential in fields of biosensing, magnetic 
resonance imaging, anti-biofouling, and cancer therapy (Cheng et al., 2017; Jiang et al., 2019; Li et al., 2019; Wang et al., 2019; Śálek et al., 2020). Between the two main IONzymes $\mathrm{Fe}_{3} \mathrm{O}_{4}$ and $\mathrm{Fe}_{2} \mathrm{O}_{3}$, most attention was paid on $\mathrm{Fe}_{3} \mathrm{O}_{4}$ due to the relatively higher saturation magnetization and simpler synthesis procedures. However, the ferrous ions of $\mathrm{Fe}_{3} \mathrm{O}_{4}$ may raise its toxic risk and make it chemically unstable (Chen et al., 2012). Therefore, $\mathrm{Fe}_{2} \mathrm{O}_{3}$ nanozymes should be better candidates for applications. However, their enzyme-mimicking activities are relatively low enough to meet a variety of specific application requirements (e.g., biosensing, antimicrobial therapy). Furthermore, it remains a great challenge to synthesize ultrafine $\mathrm{Fe}_{2} \mathrm{O}_{3}$ nanoparticles with both controllable and uniform sizes, as well as to eliminate nanoparticle aggregation, which could inevitably affect their enzyme-like activity during catalytic reaction.

Among the huge family of nanozymes, great attention was also paid on carbon nanomaterials due to their excellent nanozymatic activities, diverse structures, and good biocompatibility (Sun et al., 2017; Wang et al., 2018). Especially, their structural merits such as large surface area and good mechanical properties make them an ideal support for anchoring metal/metal oxide nanozymes to form hybrid nanozymes and to inhibit the possible agglomeration of nanoparticles (Tao et al., 2013). Wang Q. et al. (2017) reported that $\mathrm{Fe}_{3} \mathrm{O}_{4}$ nanoparticles loaded on 3D porous graphene exhibited good dispersibility as well as stability. Moreover, their high electrical conductivity could facilitate electron transfer in many redox reactions, displaying a synergistic effect on the catalytic properties of metal/metal oxide (Yang et al., 2014). Such promotion effect was also applicable for upregulating enzyme-mimicking activities of metal/metal oxide nanozymes, thus leading to greatly enhanced activities compared to their single component. For instance, the peroxidase-like activity of $\mathrm{Pt}$ and $\mathrm{Fe}_{3} \mathrm{O}_{4}$ was remarkably increased when hybridized with carbon nanodots or $\mathrm{C}_{3} \mathrm{~N}_{4}$ nanoflakes (Fan et al., 2018; Wang et al., 2018).

Recently, atomic layer deposition (ALD), as a gas-phase film deposition technology, has been demonstrated to be an advanced avenue in the preparation of ultrafine nanoparticles (Marichy and Pinna, 2013; Zhang and Qin, 2018). Owing to its self-limiting characteristic, it is capable of synthesizing nanoparticles with accurate size control at the atomic level. Zhang et al. reported that a series of Pt species, including single Pt atoms, Pt clusters, and Pt nanoparticles, could be easily fabricated by use of ALD (Sun et al., 2013). Furthermore, ALD can be served as a powerful approach to prepare hybrid nanomaterials due to its good step coverage over substrates with a complicated structure (Marichy and Pinna, 2013). Our previous study found that carbon nanotubes and graphene-supported nanoparticles with adjustable size and good distribution can be achieved by ALD (Zhang et al., 2015, 2016, 2018), which cannot be fulfilled by traditional method and confirms again the superiority of ALD. Furthermore, it has been demonstrated that the interface structure of nanozymes could also be precisely engineered by ALD to tune their enzymemimicking activities (Chen et al., 2020). However, until now there is no report on fabricating carbon-based IONzymes by ALD.

Hence, in this study, CNT-supported $\mathrm{Fe}_{2} \mathrm{O}_{3}$ nanozymes $\left(\mathrm{Fe}_{2} \mathrm{O}_{3} / \mathrm{CNTs}\right)$ were fabricated to solve the problems of aggregation and relatively low activity of the $\mathrm{Fe}_{2} \mathrm{O}_{3}$ nanozyme. ALD was adopted, for the first time, to precisely synthesize CNT-supported $\mathrm{Fe}_{2} \mathrm{O}_{3}$ nanoparticles with good uniformity and dispersibility. With the adjustment of cycle numbers, ultrasmall $\mathrm{Fe}_{2} \mathrm{O}_{3}$ nanoparticles with size down to $1 \mathrm{~nm}$ could be accurately achieved. The uniform and ultrafine $\mathrm{Fe}_{2} \mathrm{O}_{3}$ nanoparticles, as well as the synergistic effect of CNTs, contributed to an excellent enzyme-mimicking activity of the $\mathrm{Fe}_{2} \mathrm{O}_{3} / \mathrm{CNT}$ hybrid nanozyme, which made it an efficient peroxidase mimic for the catalytic conversion of a chromogenic substrate of $3,3^{\prime}, 5,5^{\prime}$ tetramethylbenzidine (TMB) and for colorimetric probe in dopamine (DA) sensing.

\section{MATERIALS AND METHODS}

\section{Materials}

Carbon nanotubes (CNTs) with diameter of 20-30 nm and length of $0.5-2 \mu \mathrm{m}$ were purchased from Shenzhen Nanotech Port Co., Ltd. (China). Raw CNTs were treated in $\mathrm{HNO}_{3}$ (68 wt \%) at $140^{\circ} \mathrm{C}$ for $4 \mathrm{~h}$ to remove possible catalyst residues and provide nuclear sites for subsequent ALD processes. Ferrocene, dimethyl sulfoxide (DMSO), hydrogen peroxide $\left(\mathrm{H}_{2} \mathrm{O}_{2}\right)$, dopamine, and $3,3^{\prime}, 5,5^{\prime}$-tetramethylbenzidine (TMB) were obtained from J\&K Scientific. All of the chemicals were used as received.

\section{Synthesis of $\mathrm{Fe}_{2} \mathrm{O}_{3} / \mathrm{CNTs}$ by ALD}

Firstly, treated CNTs were dispersed in ethanol under ultrasonic agitation and dropped onto quartz wafers. Then, the wafers were placed into an ALD chamber and the ALD process was carried out in a homemade and self-heating system. For $\mathrm{Fe}_{2} \mathrm{O}_{3} \mathrm{ALD}$, both ferrocene and $\mathrm{O}_{3}$ were used as precursors and ferrocene was heated to $75^{\circ} \mathrm{C}$ to obtain optimal vapor pressure. To ensure successful $\mathrm{Fe}_{2} \mathrm{O}_{3}$ deposition, the chamber was maintained at $260^{\circ} \mathrm{C}$. The pulse, exposure, and purge time for ferrocene and $\mathrm{O}_{3}$ were $1.5 / 20 / 30$ and $0.2 / 15 / 30$ (s), respectively. The particle size of $\mathrm{Fe}_{2} \mathrm{O}_{3}$ was adjusted by ALD cycles and the samples with different ALD cycle numbers ( $n$ ) were noted as $n \mathrm{ne}_{2} \mathrm{O}_{3} / \mathrm{CNT}$ in this study. After deposition, the samples were collected for further use.

\section{Characterization}

Transmission electron microscopy (TEM) and high-resolution TEM (HRTEM) were measured on a FEI Tecnai F20 instrument. High-angle annular dark-field scanning-TEM (HAADF-STEM) images were also collected on this equipment operated at 200 $\mathrm{kV}$. X-ray photoelectron spectroscopy (XPS) data were collected with a Thermo ESCALAB 250 xi with an Al-Ka line as the radiation source. X-ray diffraction (XRD) data were recorded on a MAXima XRD-7000 diffractometer with $\mathrm{Cu} \mathrm{K \alpha}$ radiation. Inductively coupled plasma optical emission spectrometry (ICPOES; Thermo iCAP 6300) was used to determine the content of the metal in the hybrid nanozyme.

\section{Peroxidase-Mimicking Activity Assay}

A colorimetric method was adopted to estimate the peroxidase activity of $\mathrm{Fe}_{2} \mathrm{O}_{3} / \mathrm{CNT}$ samples by using $\mathrm{TMB}$ as the chromogenic substrate. Typically, the catalytic reaction was processed by adding $20 \mu \mathrm{L}$ of $\mathrm{Fe}_{2} \mathrm{O}_{3} / \mathrm{CNT}$ nanozyme (0.5 
$\mathrm{mg} / \mathrm{mL}), 80 \mu \mathrm{L}$ of TMB $(2.5 \mathrm{mM})$, and $100 \mu \mathrm{L}$ of $\mathrm{H}_{2} \mathrm{O}_{2}(10 \mathrm{mM})$ into a $2 \mathrm{~mL}$ tube. The final volume was adjusted to $1 \mathrm{~mL}$ by adding $800 \mu \mathrm{L}$ NaAc buffer (0.2 M, pH 3.6). The mixed solutions were incubated at $37^{\circ} \mathrm{C}$ for $10 \mathrm{~min}$. Then, the UV-vis absorbance of oxidized $\mathrm{TMB}\left(\mathrm{TMB}_{\mathrm{ox}}\right)$ at a wavelength of $652 \mathrm{~nm}$ was immediately recorded. Furthermore, the enzyme-like property was evaluated according to Yan's protocol (Jiang et al., 2018). The experiments were carried out at $37^{\circ} \mathrm{C}$ in NaAc-HAc buffer (0.2 M, pH 4.0) containing TMB ( $4 \mu \mathrm{L}$ of $\left.10 \mathrm{mg} \mathrm{mL}^{-1}\right)$ and $\mathrm{H}_{2} \mathrm{O}_{2}$ (1 M). The time-dependent absorbance curves were immediately recorded at a $10 \mathrm{~s}$ interval within $400 \mathrm{~s}$, and the nanozyme activity expressed in units (U) was calculated according to the following equation:

$$
b_{\text {nanozyme }}=\frac{V}{\varepsilon l} \times \frac{\Delta A}{\Delta t}
$$

where $b_{\text {nanozyme }}$ is the nanozyme activity $(\mathrm{U}), V$ is the total volume of reaction solution $(\mu \mathrm{L}), \varepsilon$ is the molar absorption coefficient of the TMB substrate $\left(39,000 \mathrm{M}^{-1} \mathrm{~cm}^{-1}\right.$ at $\left.652 \mathrm{~nm}\right)$, $l$ is the optical path length through reaction solution $(\mathrm{cm})$, and $\Delta A / \Delta t$ is the initial rate of the absorbance change (per minute). The specific activity of the nanozyme was determined using the following equation:

$$
a_{\text {nanozyme }}=\frac{b_{\text {nanozyme }}}{m}
$$

where $a_{\text {nanozyme }}$ is the specific activity of the nanozyme ( $\mathrm{U} \mathrm{mg}^{-1}$ ) and $m$ is the nanozyme amount for each assay (mg).

\section{Steady-State Kinetic Analysis}

Kinetic experiments were carried out in a $2 \mathrm{~mL}$ cuvette with $1 \mathrm{~mL} \mathrm{NaAc}$ buffer $(0.2 \mathrm{M}, \mathrm{pH} 3.6)$ containing $10 \mu \mathrm{g}$ $10 \mathrm{Fe}_{2} \mathrm{O}_{3} /$ CNTs. Both TMB and $\mathrm{H}_{2} \mathrm{O}_{2}$ were also added and tested in a time-course model at $37^{\circ} \mathrm{C} . \mathrm{TMB}_{\mathrm{ox}}$ at $652 \mathrm{~nm}$ was recorded every $30 \mathrm{~s}$ in the range of $0-10 \mathrm{~min}$, and the initial rates of two different substrates were determined. The kinetic assay with TMB as substrate was conducted by varying concentrations of TMB with the concentration of $\mathrm{H}_{2} \mathrm{O}_{2}$ fixed at $0.1 \mathrm{nM}$, and vice versa. The key kinetic parameters, such as Michaelis-Menten constant $\left(K_{m}\right)$, catalytic efficiency $\left(K_{\text {cat }}\right)$, and specific activity were calculated by fitting the initial velocity data to the Michaelis-Menten equation: $1 / \mathrm{V}$ $=K_{m} / V_{m}\left(1 /[S]+1 / K_{m}\right)$, where $V$ represents the initial rate, $V_{m}$ is the maximal rate of the enzyme-like reaction, $K_{m}$ corresponds to the Michaelis-Menten constant, and [S] is the substrate concentration.

\section{Colorimetric Sensing of DA}

Colorimetric sensing of DA was evaluated using the $10 \mathrm{Fe}_{2} \mathrm{O}_{3} / \mathrm{CNTs}$ hybrid nanozyme under the optimized conditions. The experiments were carried out as follows: $80 \mu \mathrm{L}$ of TMB $\left(0.2 \mathrm{mM}\right.$ in DMSO), $100 \mu \mathrm{L}$ of $\mathrm{H}_{2} \mathrm{O}_{2}$ $(0.1 \mathrm{mM})$, and $5 \mu \mathrm{L}$ of $10 \mathrm{Fe}_{2} \mathrm{O}_{3} / \mathrm{CNTs}(0.5 \mathrm{mg} / \mathrm{mL})$ were
A

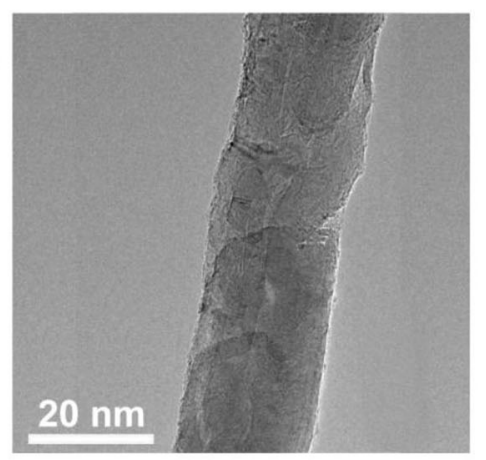

D

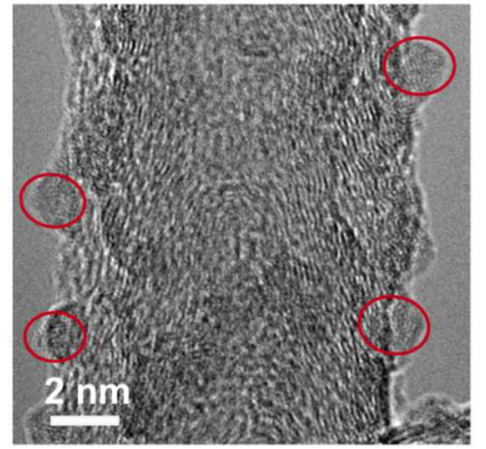

B

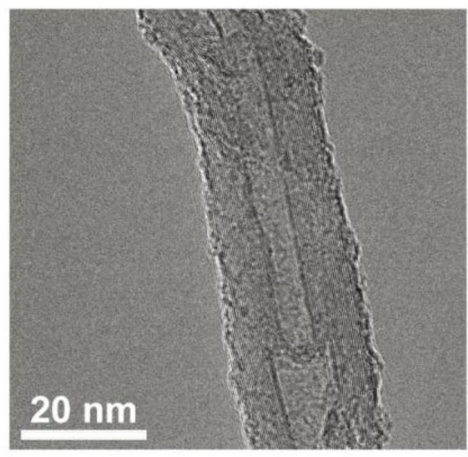

E

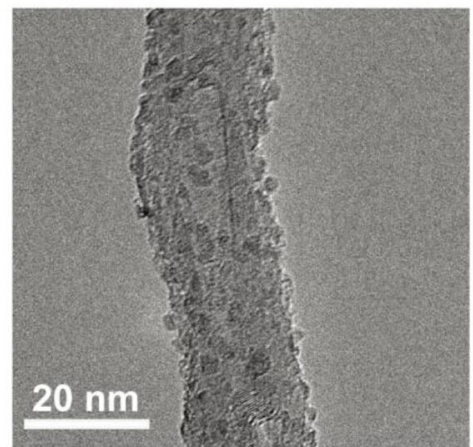

C

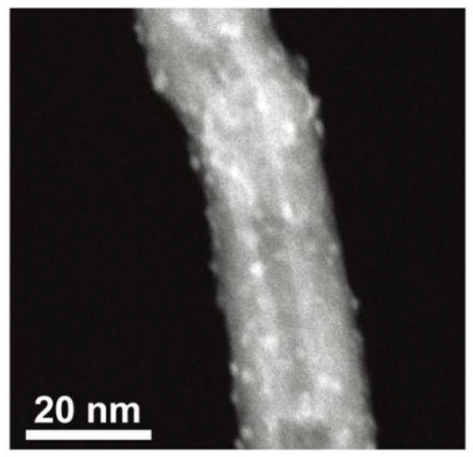

$\mathbf{F}$

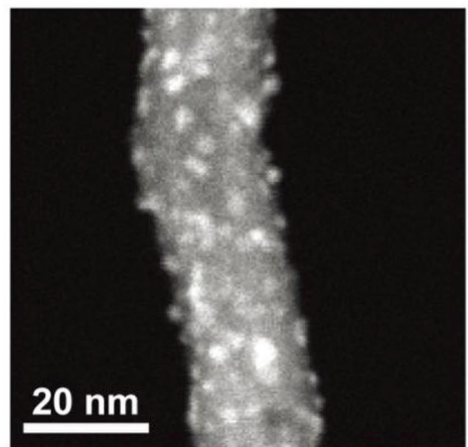

FIGURE 1 | TEM images of $5 \mathrm{Fe}_{2} \mathrm{O}_{3} / \mathrm{CNTS}$ (A), TEM image (B), HAADF image (C), HRTEM image of $10 \mathrm{Fe}_{2} \mathrm{O}_{3} / \mathrm{CNTS}$ (D), HRTEM image (E), and HAADF image (F) of $15 \mathrm{Fe}_{2} \mathrm{O}_{3} / \mathrm{CNTS}$. 

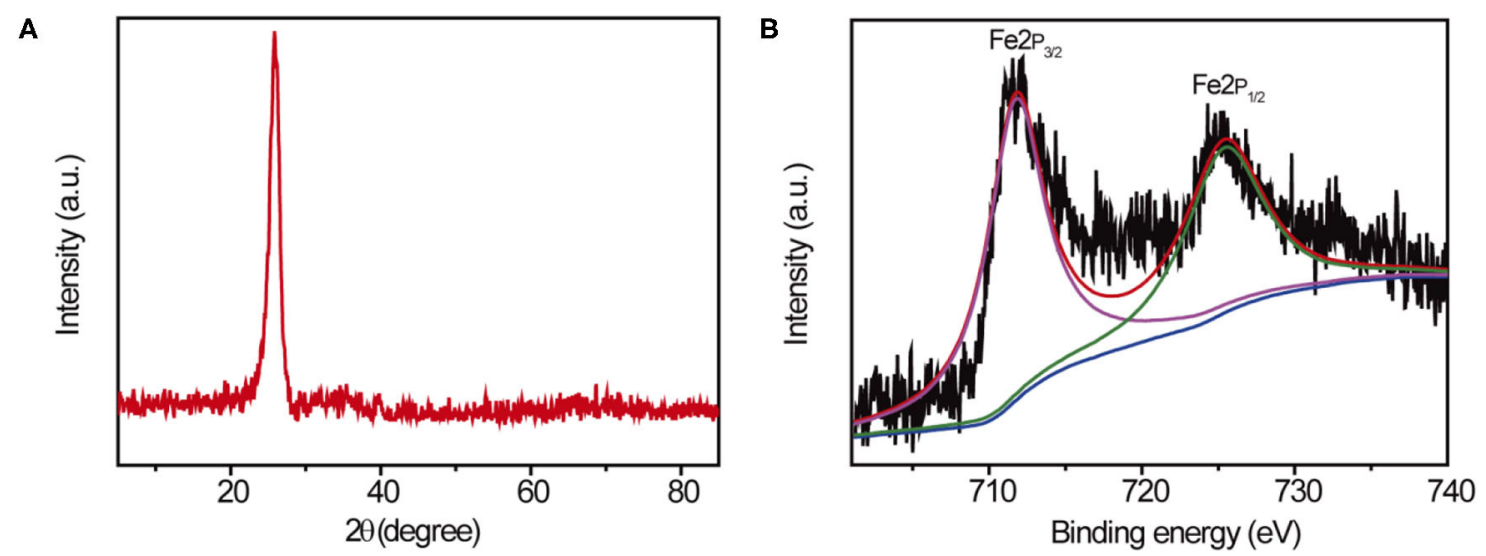

FIGURE 2 | (A) XRD spectra of $\mathrm{Fe}_{2} \mathrm{O}_{3} / \mathrm{CNTS}$ and (B) the XPS core level of Fe2p.
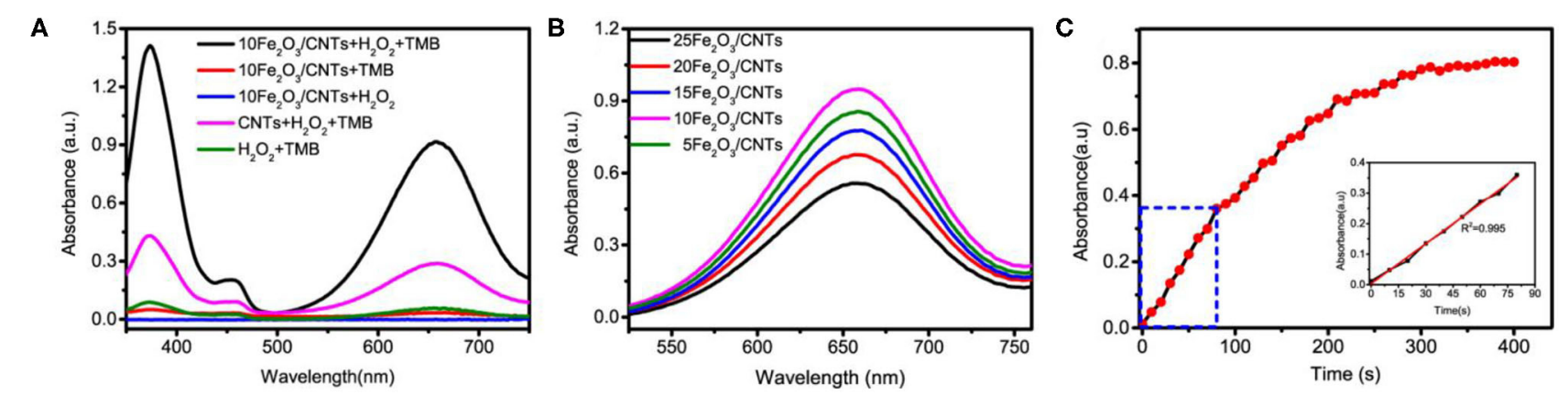

FIGURE 3 | (A) UV-vis spectra of monitoring oxidized TMB catalyzed by different systems. (B) Peroxidase-like activities of Fe ${ }_{2} \mathrm{O}_{3} / \mathrm{CNTS}$ with different Fe $\mathrm{O}_{3}$ cycles. (C) The absorbance-time curves of the TMB chromogenic reaction catalyzed by the $10 \mathrm{Fe}_{2} \mathrm{O}_{3} / \mathrm{CNTs}$.

successively added to $750 \mu \mathrm{L}$ of $\mathrm{NaAc}$ buffer $(0.2 \mathrm{M}, \mathrm{pH}$ 3.6). Then, $50 \mu \mathrm{L}$ of $\mathrm{DA}$ with different concentration was added and the mixture was incubated at $37^{\circ} \mathrm{C}$ for $10 \mathrm{~min}$, followed by monitoring of the UV-vis absorbance of $\mathrm{TMB}_{\mathrm{ox}}$ at $652 \mathrm{~nm}$.

\section{RESULTS AND DISCUSSION}

In order to characterize the morphology of the as-deposited $\mathrm{Fe}_{2} \mathrm{O}_{3} / \mathrm{CNT}$ samples, TEM measurements were conducted; the results are depicted in Figure 1. For the sample of $5 \mathrm{Fe}_{2} \mathrm{O}_{3} / \mathrm{CNTs}$, almost no $\mathrm{Fe}_{2} \mathrm{O}_{3}$ nanoparticle can be distinguished from surfaces of CNTs due to its low loading content (Figure 1A). With increasing ALD cycles, it remained difficult to identify the existence of $\mathrm{Fe}_{2} \mathrm{O}_{3}$ in the TEM image of $10 \mathrm{Fe}_{2} \mathrm{O}_{3} / \mathrm{CNT}$ (Figure 1B), but the HAADF image (Figure 1C) recorded at the same region reveals visibly the successful deposition of $\mathrm{Fe}_{2} \mathrm{O}_{3}$ nanoparticles on CNTs. This can be clearly distinguished from the HRTEM image as depicted in Figure 1D. It is obvious that these nanoparticles are uniformly distributed with diameter of around $1 \mathrm{~nm}$. In addition, it is worth noting that the as-synthesized $\mathrm{Fe}_{2} \mathrm{O}_{3}$ by ALD is amorphous with no visible crystalline structure found in HRTEM images. When 15 cycles of
$\mathrm{Fe}_{2} \mathrm{O}_{3}$ were applied, a higher density of nanoparticles with larger size of around $2 \mathrm{~nm}$ on CNTs was observed both in HRTEM (Figure 1E) and HAADF (Figure 1F) images. These results fully demonstrate that ALD can be served as a novel avenue to synthesize $\mathrm{Fe}_{2} \mathrm{O}_{3}$ nanoparticles with ultrasmall and adjustable size, which cannot be fulfilled by traditional method and fully reveals the superiority of ALD.

Further studies were conducted in characterization of the chemical structure of $10 \mathrm{Fe}_{2} \mathrm{O}_{3} / \mathrm{CNT}$ s by XRD measurement, and the spectra of $10 \mathrm{Fe}_{2} \mathrm{O}_{3} / \mathrm{CNT}$ s are presented in Figure 2A. The main diffraction peak located at $2 \theta=23.8^{\circ}$ belongs to typical XRD spectra of CNTs. However, no characteristic peak of iron oxide could be found in the spectra, which matches well with the abovementioned TEM results. As revealed by ICP analysis, the content of $\mathrm{Fe}_{2} \mathrm{O}_{3}$ in $10 \mathrm{Fe}_{2} \mathrm{O}_{3} / \mathrm{CNT}$ was as low as $2.1 \mathrm{wt} \%$ (results not provided). Actually, similar results have been achieved in our previous study (Zhang et al., 2015) and the unobservable XRD signal of $\mathrm{Fe}_{2} \mathrm{O}_{3}$ was ascribed to its poor crystallinity and low content, when few cycles of ALD were conducted. In addition, XPS test was also performed to investigate the surface elemental composition of $10 \mathrm{Fe}_{2} \mathrm{O}_{3} / \mathrm{CNT}$. Deconvolution of Fe $2 \mathrm{p}$ corelevel spectra shown in Figure 2B reveals that there are two main peaks located at 712.6 and $726.1 \mathrm{eV}$, which can be ascribed to 
Fe2p 3/2 and Fe2p 1/2, respectively. These results demonstrated the $3+$ valence state of $\mathrm{Fe}$ species in $10 \mathrm{Fe}_{2} \mathrm{O}_{3} / \mathrm{CNTs}$. Meanwhile, the existence of an associate satellite peak located at $718.9 \mathrm{eV}$ could correspond to the characteristic XPS spectra of $\mathrm{Fe}_{2} \mathrm{O}_{3}$. The combined results of TEM, XRD, and XPS strongly support that $\mathrm{Fe}_{2} \mathrm{O}_{3}$ was successfully deposited on CNTs by ALD.

\section{The Peroxidase-Mimicking Activity of $\mathrm{Fe}_{2} \mathrm{O}_{3} / \mathrm{CNTs}$}

With assistance of the ALD method, it is expected that the as-synthesized $\mathrm{Fe}_{2} \mathrm{O}_{3} / \mathrm{CNT}$ samples with ultrafine particle size and good dispersibility possess excellent enzyme-mimicking activities. The peroxidase-like activities of $\mathrm{Fe}_{2} \mathrm{O}_{3} / \mathrm{CNT}$ samples were manifested through TMB oxidation in the presence of $\mathrm{H}_{2} \mathrm{O}_{2}$ into a charge transfer product $\left(\mathrm{TMB}_{\mathrm{ox}}\right)$. Several control experiments were carried out to confirm the catalytic nature. It can be seen in Figure 3A that neither $\mathrm{H}_{2} \mathrm{O}_{2}$ nor TMB alone was capable of inducing catalytic reaction and no significant absorbance peak was generated. When both substrates were presented, the catalytic oxidation rate was

TABLE 1 | Typical specific peroxidase-like activity of $10 \mathrm{Fe}_{2} \mathrm{O}_{3} / \mathrm{CNTS}$ and its comparison with other nanozymes.

\begin{tabular}{lcl}
\hline Nanozymes & $\begin{array}{c}\text { Specific peroxidase } \\
\text { activity }\left(\mathbf{U} \mathbf{~ m g}^{-\mathbf{1}}\right)\end{array}$ & References \\
\hline $\mathrm{Fe}_{3} \mathrm{O}_{4} \mathrm{NPS}$ & 5.143 & Jiang et al., 2018 \\
$\mathrm{IONPS}$ & 8.5 & Šálek et al., 2020 \\
Carbon NPs & 3.302 & Jiang et al., 2018 \\
$\mathrm{Fe}-\mathrm{N}-\mathrm{C}$ & 57.76 & Niu et al., 2019 \\
$\mathrm{Fe}-\mathrm{N}-\mathrm{C}$ & 25.33 & Jiao et al., 2020 \\
This work & 24.5 & -
\end{tabular}

accelerated by $10 \mathrm{Fe}_{2} \mathrm{O}_{3} / \mathrm{CNT}$ in comparison to bare CNTs, as revealed by a great enhancement in the absorbance at $652 \mathrm{~nm}$. It can be concluded that the hybridization of CNTs with uniform and ultra-small $\mathrm{Fe}_{2} \mathrm{O}_{3}$ nanoparticles contributes to great enhancement in peroxidase-like activity.

Since ALD has a unique advantage of flexible control over cycles, it enables the optimization of the peroxidase-mimicking activity by adjusting the particle size of $\mathrm{Fe}_{2} \mathrm{O}_{3}$. The peroxidaselike activity of $\mathrm{Fe}_{2} \mathrm{O}_{3} / \mathrm{CNT}$ samples with different cycles was also tested, and the results are shown in Figure 3B. It is obvious that the activity was enhanced with increase in ALD cycle $(n<10)$ but showed an opposite trend when more than 10 cycles of $\mathrm{Fe}_{2} \mathrm{O}_{3}$ ALD were conducted. Among them, $10 \mathrm{Fe}_{2} \mathrm{O}_{3} / \mathrm{CNT}$ presented the highest activity, which might be due to the hybridization of CNTs with $\mathrm{Fe}_{2} \mathrm{O}_{3}$, as well as the ultrafine nanoparticles with good distribution. The relative low activity of $5 \mathrm{Fe}_{2} \mathrm{O}_{3} / \mathrm{CNT}$ might be attributed to the low loading content of $\mathrm{Fe}_{2} \mathrm{O}_{3}$ in the hybrid nanozyme, while the nanoparticle stacking as well as the blocking access to active sites resulted in the low activity of samples with more than 10 cycles. As depicted in Figure 3C, the specific activity determined according to the protocol of Yan's group (Jiang et al., 2018) shows that the absorbance is linear to reaction time in the first minutes. By choosing $80 \mathrm{~s}$ as the initial

TABLE 2 | Typical Michaelis-Menten constant and maximum velocity for $\mathrm{H}_{2} \mathrm{O}_{2}$ and TMB substrates and their comparison with HRP.

\begin{tabular}{lccc}
\hline Catalyst & Substrate & $\boldsymbol{K}_{\boldsymbol{m}}$ [mM] & $\boldsymbol{V}_{\boldsymbol{m a x}}\left[\mathbf{1 0} \mathbf{1 0}^{-\mathbf{8}} \mathbf{M s}^{-\mathbf{1}} \mathbf{]}\right.$ \\
\hline $10 \mathrm{Fe}_{2} \mathrm{O}_{3} / \mathrm{CNTS}$ & $\mathrm{TMB}$ & 0.515 & 14.61 \\
$10 \mathrm{Fe}_{2} \mathrm{O}_{3} / \mathrm{CNTS}$ & $\mathrm{H}_{2} \mathrm{O}_{2}$ & 0.704 & 17.43 \\
$\mathrm{HRP}(\mathrm{GaO}$ et al., 2007) & $\mathrm{TMB}$ & 0.43 & 10 \\
$\mathrm{HRP}$ (Gao et al., 2007) & $\mathrm{H}_{2} \mathrm{O}_{2}$ & 3.7 & 8.71
\end{tabular}
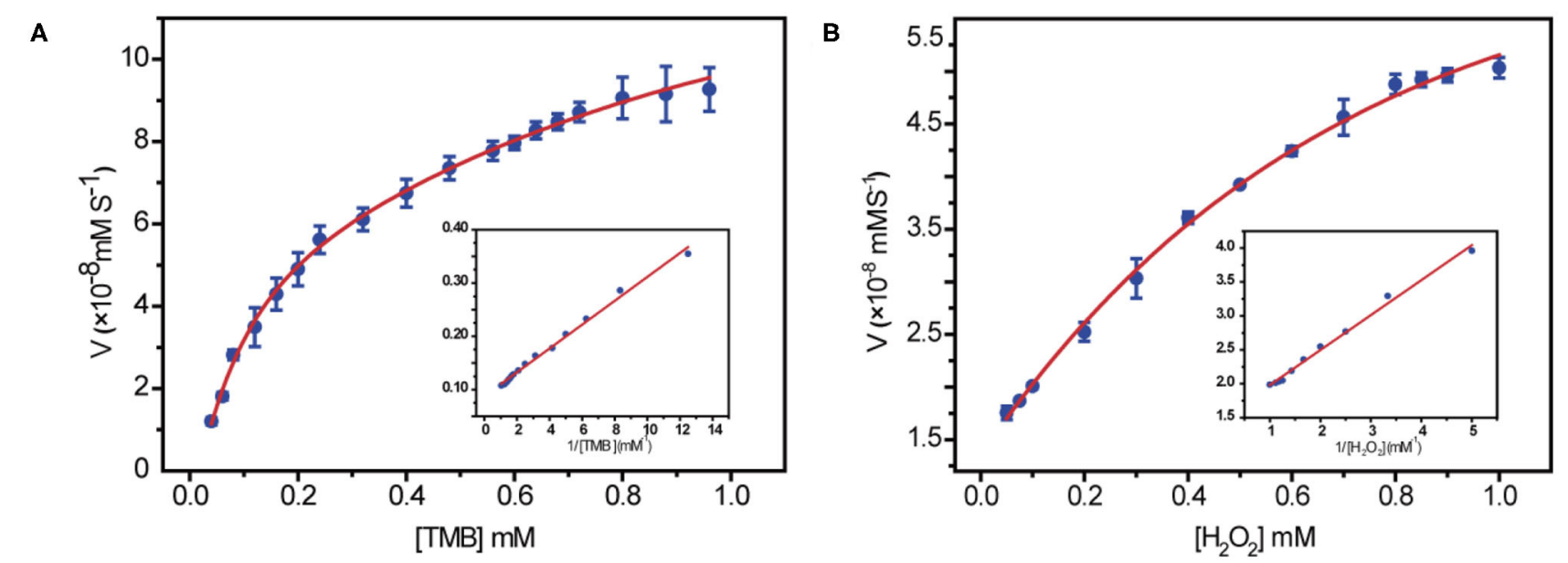

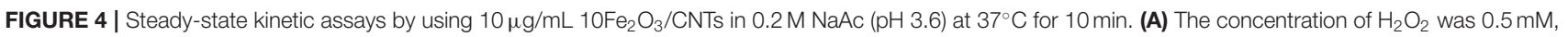
and the TMB concentration was varied. (B) The concentration of TMB was $0.4 \mathrm{mM}$, and the $\mathrm{H}_{2} \mathrm{O}_{2}$ concentration was varied. Insets are the Lineweaver-Burk plots of the double reciprocal of the Michaelis-Menten equation, with the concentration of one substrate fixed and the other varied. Error bars shown represent the standard error derived from three repeated measurements. 
A

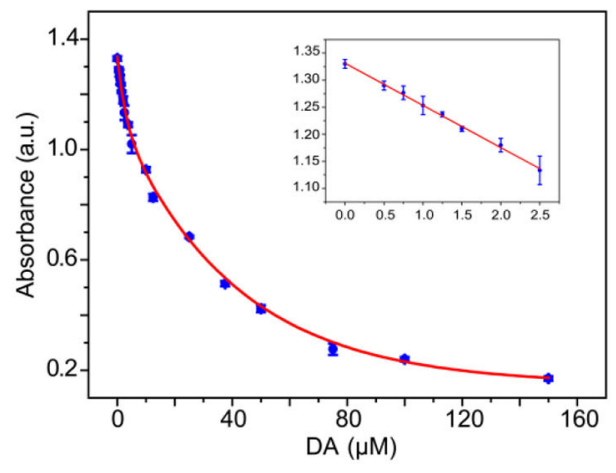

B

\begin{tabular}{|c|c|c|c|c|}
\hline Nanozymes & $\begin{array}{l}\text { LOD } \\
(\mu \mathrm{M}) \\
\end{array}$ & $\begin{array}{l}\text { Linear range } \\
(\mu \mathrm{M})\end{array}$ & $\begin{array}{c}\text { Contents of } \\
\text { nanozyme }(\mu \mathrm{g})\end{array}$ & Ref \\
\hline this work & 0.11 & $10-80$ & 2.5 & \\
\hline AuMS & $\begin{array}{c}0.01 \\
2\end{array}$ & $0.5-25$ & 10 & $\begin{array}{c}\text { (Ray et al. } \\
2020 \text { ) }\end{array}$ \\
\hline h-CuS NCs & 1.67 & $2-150$ & 20 & $\begin{array}{c}\text { (Zhu et al. } \\
\text { 2019) }\end{array}$ \\
\hline CuS-rGO & 0.48 & $2-100$ & 10 & $\begin{array}{c}\text { (Dutta et al. } \\
\text { 2015) }\end{array}$ \\
\hline Pt/hBNNS & 0.76 & $2-50$ & 7 & $\begin{array}{l}\text { (Ivanova et } \\
\text { al. 2019) }\end{array}$ \\
\hline
\end{tabular}

FIGURE 5 | (A) The absorbance of oxidized TMB in the DA detection system in the presence of DA. (Insets) The linear calibration plot and the optical image for DA detection using $10 \mathrm{Fe}_{2} \mathrm{O}_{3} / \mathrm{CNTs}$. The error bars indicate the standard deviation of three repeated measurements. (B) Comparison of the sensing properties of typical nanozymes (Dutta et al., 2015; Ivanova et al., 2019; Zhu et al., 2019; Ray et al., 2020).

rate period, the calculated peroxidase activity of $10 \mathrm{Fe}_{2} \mathrm{O}_{3} / \mathrm{CNTs}$ was $24.5 \mathrm{U} \mathrm{mg}^{-1}$ (the inset in Figure 3C). It is obvious that this value is higher than that of reported IONzymes and carbon-based nanozymes (Table 1) and very close to the highest specific activity of the $\mathrm{Fe}-\mathrm{N}-\mathrm{C}$ single atom nanozyme, demonstrating the excellent performance of $10 \mathrm{Fe}_{2} \mathrm{O}_{3} / \mathrm{CNTs}$ fabricated by ALD.

\section{Steady-State Kinetic Theory of $10 \mathrm{Fe}_{2} \mathrm{O}_{3} / \mathrm{CNTs}$}

In order to get a clear understanding of the intrinsic mechanism for peroxidase activity enhancement of $10 \mathrm{Fe}_{2} \mathrm{O}_{3} / \mathrm{CNT}$ samples, the kinetic was exploited by altering the concentration of one substrate while keeping constant of the other. A set of concentrations for each substrate was recorded in a timecourse mode, and the initial rate of TMB and $\mathrm{H}_{2} \mathrm{O}_{2}$, which is the slope of $\triangle \mathrm{A} 652$ per unit time ( $\mathrm{min}$ ), was obtained by applying the Beer-Lambert law. The collected data were fitted based on the Michaelis-Menten equation, and the nanozymatic parameters were calculated with the typical Lineweaver-Burk double reciprocal plots as depicted in Figure 4.

The key parameters of $K_{m}$ and $V_{\max }$ are listed in Table 2. Since $K_{m}$ is identified as the indicator of the affinity of enzyme to substrates, achieving low $K_{m}$ and high $V_{\max }$ is important to ensure better catalytic performance. It is obvious that the $10 \mathrm{Fe}_{2} \mathrm{O}_{3} /$ CNTs displayed smaller $K_{m}$ values for $\mathrm{H}_{2} \mathrm{O}_{2}$, indicating a better affinity to $\mathrm{H}_{2} \mathrm{O}_{2}$ and a relatively low concentration of $\mathrm{H}_{2} \mathrm{O}_{2}$ needed for achieving a high response of $10 \mathrm{Fe}_{2} \mathrm{O}_{3} / \mathrm{CNTs}$ in catalytic reaction. This result is consistent with the report that in the reaction of TMB oxidation with $\mathrm{H}_{2} \mathrm{O}_{2}$, decomposition of $\mathrm{H}_{2} \mathrm{O}_{2}$ is the rate-determining step (Zhao et al., 2008), whereby the $K_{m}$ for TMB is close to the natural HRP enzyme, suggesting its good binding affinity for TMB.

\section{Sensitivity of $10 \mathrm{Fe}_{2} \mathrm{O}_{3} / \mathrm{CNTs}$ for Detection of DA}

A variety of biosensors have been established based on the excellent enzyme-mimicking activities of nanozymes. As an essential neurotransmitter, dopamine (DA) is critically involved in a variety of motor and non-motor information transmission and affecting human emotions and perceptions (Paval, 2017; Sgambato-Faure and Tremblay, 2018). DA disorder will cause a series of diseases (Ashok et al., 2017; Sgambato-Faure and Tremblay, 2018). For instance, if too much dopamine is secreted, it can lead to neurological dysfunction. Hence, it is necessary to develop a simple and sensitive approach to detect the DA level. Inspired by the behavior that the existence DA in catalytic reaction solution will inhibit peroxidasemimicking activity of the $10 \mathrm{Fe}_{2} \mathrm{O}_{3} / \mathrm{CNTs}$, a colorimetric method was employed to determination of DA. Figure $\mathbf{5 A}$ shows the absorbance response of $\mathrm{TMB}_{\mathrm{ox}}$ in the system when different concentrations of DA were added. A typical linear calibration plot was obtained in the $0-25 \mu \mathrm{M}$ concentration range with a limit of detection (LOD) of $0.11 \mu \mathrm{M}$. The LOD was calculated by using the typical formula LOD $=3 \sigma / k$, where $\sigma$ is the standard deviation for the target-blank sample and $k$ stands for the slope of the calibration curve. This approach provides a convenient and sensitive method for sensing of DA. As shown in Figure 5B, the LOD of our system is not the lowest by comparing with typical Au nanoparticles, hollow $\mathrm{CuS}$ nanocubes, and Pt nanoparticles. However, it is worth noting that the concentration of the nanozyme used in our approach is the lowest, which demonstrates that the $10 \mathrm{Fe}_{2} \mathrm{O}_{3} / \mathrm{CNT}$ hybrids fabricated by ALD are a promising candidate for DA biosensing applications.

\section{CONCLUSIONS}

To sum up, CNT-loaded $\mathrm{Fe}_{2} \mathrm{O}_{3}$ nanoparticles with uniform distribution and precise size control can be easily prepared by ALD. The CNTs not only serve as the support to inhibit possible aggregation of $\mathrm{Fe}_{2} \mathrm{O}_{3}$ nanoparticles but also act as activity enhancer for $\mathrm{Fe}_{2} \mathrm{O}_{3}$, which endows $\mathrm{Fe}_{2} \mathrm{O}_{3} / \mathrm{CNT}$ hybrids with an excellent peroxidase activity. In our approach, the peroxidase activity could be optimized by adjusting the cycle number of $\mathrm{Fe}_{2} \mathrm{O}_{3}$ ALD and the highest activity was achieved by $10 \mathrm{Fe}_{2} \mathrm{O}_{3} / \mathrm{CNTs}$, due to the well-distributed and ultrafine $\mathrm{Fe}_{2} \mathrm{O}_{3}$ 
nanoparticles on the surface of CNTs. The steady kinetic assay demonstrated that $10 \mathrm{Fe}_{2} \mathrm{O}_{3} / \mathrm{CNTs}$ show good binding affinity to both TMB and $\mathrm{H}_{2} \mathrm{O}_{2}$. In addition, a colorimetric method for sensing of DA was established based on the excellent activity of $10 \mathrm{Fe}_{2} \mathrm{O}_{3} / \mathrm{CNTs}$, which presented a good sensitivity with LOD as low as $0.11 \mu \mathrm{M}$. Based on the abovementioned results, the unique advantage of ALD by precise and controllable nanomaterial fabrication enables a novel avenue for nanozyme synthesis with finely tunable activities, which can be convenient for in-depth investigation and understanding of the catalytic mechanism of nanozymes and broaden also their application in biosensing and other areas.

\section{DATA AVAILABILITY STATEMENT}

All datasets generated for this study are included in the article/supplementary material.

\section{REFERENCES}

Ashok, A. H., Marques, T. R., Jauhar, S., Nour, M. M., Goodwin, G. M., Young, A. H., et al. (2017). The dopamine hypothesis of bipolar affective disorder: the state of the art and implications for treatment. Mol. Psychiatry 22, 666-679. doi: $10.1038 / \mathrm{mp} .2017 .16$

Chen, Y., Yuchi, Q., Li, T., Yang, G., Miao, J., Huang, C., et al. (2020). Precise engineering of ultra-thin $\mathrm{Fe} 2 \mathrm{O} 3$ decorated Pt-based nanozymes via atomic layer deposition to switch off undesired activity for enhanced sensing performance. Sens. Actuat. B 305:127436. doi: 10.1016/j.snb.2019.127436

Chen, Z., Yin, J. J., Zhou, Y. T., Zhang, Y., Song, L., Song, M., et al. (2012). Dual enzyme-like activities of iron oxide nanoparticles and their implication for diminishing cytotoxicity. ACS Nano 6, 4001-4012. doi: 10.1021/nn300291r

Cheng, N., Song, Y., Zeinhom, M. M. A., Chang, Y. C., Sheng, L., Li, H., et al. (2017). Nanozyme-mediated dual immunoassay integrated with smartphone for use in simultaneous detection of pathogens. ACS Appl. Mater. Interfaces 9, 40671-40680. doi: 10.1021/acsami.7b12734

Dutta, S., Ray, C., Mallick, S., Sarkar, S., Sahoo, R., Negishi, Y., et al. (2015). A gel-based approach to design hierarchical CuS decorated reduced graphene oxide nanosheets for enhanced peroxidase-like activity leading to colorimetric detection of dopamine. J. Phys. Chem. C 119, 23790-23800. doi: 10.1021/acs.jpcc.5b08421

Fan, L., Xu, X., Zhu, C., Han, J., Gao, L., Xi, J., et al. (2018). Tumor catalyticphotothermal therapy with yolk-shell Gold@Carbon nanozymes. ACS Appl. Mater. Interfaces 10, 4502-4511. doi: 10.1021/acsami.7b17916

Gao, L., Zhuang, J., Nie, L., Zhang, J., Zhang, Y., Gu, N., et al. (2007). Intrinsic peroxidase-like activity of ferromagnetic nanoparticles. Nat. Nanotechnol. 2, 577-583. doi: 10.1038/nnano.2007.260

Ivanova, M. N., Grayfer, E. D., Plotnikova, E. E., Kibis, L. S., Darabdhara, G., Boruah, P. K., et al. (2019). Pt-decorated boron nitride nanosheets as artificial nanozyme for detection of dopamine. ACS Appl. Mater. Interfaces 11, 22102-22112. doi: 10.1021/acsami.9b04144

Jiang, B., Duan, D., Gao, L., Zhou, M., Fan, K., Tang, Y., et al. (2018). Standardized assays for determining the catalytic activity and kinetics of peroxidase-like nanozymes. Nat. Protoc. 13, 1506-1520. doi: 10.1038/s41596-018-0001-1

Jiang, D., Ni, D., Rosenkrans, Z. T., Huang, P., Yan, X., and Cai, W. (2019). Nanozyme: new horizons for responsive biomedical applications. Chem. Soc. Rev. 48, 3683-3704. doi: 10.1039/C8CS00718G

Jiao, L., Wu, J., Zhong, H., Zhang, Y., Xu, W., Wu, Y., et al. (2020). Densely isolated FeN4 sites for peroxidase mimicking. ACS Catal. 10, 6422-6429. doi: 10.1021/acscatal.0c01647

Li, S., Liu, X., Chai, H., and Huang, Y. (2018). Recent advances in the construction and analytical applications of metal-organic frameworks-based nanozymes. TrAC Trends Anal. Chem. 105, 391-403. doi: 10.1016/j.trac.2018.06.001

\section{AUTHOR CONTRIBUTIONS}

YY, TL, LZ, YQ, and YC conceived and carried out experiments, analyzed data, and wrote the paper. All authors read and approved the final manuscript.

\section{FUNDING}

This work was financially supported by the National Natural Science Foundation of China (31971315), the Natural Science Basic Research Plan in Shaanxi Province of China (2018JQ2038), the Innovation Capability Support Program of Shaanxi (2020TD-042), the Fundamental Research Funds for the Central Universities (3102017OQD048, 3102017OQD049), the China Postdoctoral Science Foundation (2018M633566), and the Postdoctoral Science Foundation of Shaanxi (2018BSHQYXMZZ35).

Li, W., Fan, G. C., Gao, F., Cui, Y., Wang, W., and Luo, X. (2019). High-activity Fe3O4 nanozyme as signal amplifier: a simple, low-cost but efficient strategy for ultrasensitive photoelectrochemical immunoassay. Biosens. Bioelectron. 127, 64-71. doi: 10.1016/j.bios.2018.11.043

Lin, Y., Ren, J., and Qu, X. (2014). Catalytically active nanomaterials: a promising candidate for artificial enzymes. Acc. Chem. Res. 47, 1097-1105. doi: 10.1021/ar400250z

Liu, B., and Liu, J. (2017). Surface modification of nanozymes. Nano Res. 10, 1125-1148. doi: 10.1007/s12274-017-1426-5

Marichy, C., and Pinna, N. (2013). Carbon-nanostructures coated/decorated by atomic layer deposition: growth and applications. Coord. Chem. Rev. 257, 3232-3253. doi: 10.1016/j.ccr.2013.08.007

Natalio, F., Andre, R., Hartog, A. F., Stoll, B., Jochum, K. P., Wever, R., et al. (2012). Vanadium pentoxide nanoparticles mimic vanadium haloperoxidases and thwart biofilm formation. Nat. Nanotechnol. 7, 530-535. doi: 10.1038/nnano.2012.91

Niu, X., Shi, Q., Zhu, W., Liu, D., Tian, H., Fu, S., et al. (2019). Unprecedented peroxidase-mimicking activity of single-atom nanozyme with atomically dispersed Fe-Nx moieties hosted by MOF derived porous carbon. Biosens. Bioelectron. 142:111495. doi: 10.1016/j.bios.2019.111495

Paval, D. (2017). A dopamine hypothesis of autism spectrum disorder. Dev. Neurosci. 39, 355-360. doi: 10.1159/000478725

Ray, S., Biswas, R., Banerjee, R., and Biswas, P. (2020). Gold nanoparticle intercalated mesoporous silica based nanozyme for selective colorimetric detection of dopamine. Nanoscale $A d v$. 734-745. doi: 10.1039/C9NA0 $0508 \mathrm{~K}$

Šálek, P., Golunova, A., Dvoráková, J., Pavlova, E., Macková, H., and Proks, V. (2020). Iron oxide nanozyme as catalyst of nanogelation. Mater. Lett. 269:127610. doi: 10.1016/j.matlet.2020.127610

Sgambato-Faure, V., and Tremblay, L. (2018). Dopamine and serotonin modulation of motor and non-motor functions of the non-human primate striato-pallidal circuits in normal and pathological states. J. Neural. Transm. 125, 485-500. doi: 10.1007/s00702-017-1693-z

Sun, A., Mu, L., and $\mathrm{Hu}, \mathrm{X}$. (2017). Graphene oxide quantum dots as novel nanozymes for alcohol intoxication. ACS Appl. Mater. Interfaces 9, 12241-12252. doi: 10.1021/acsami.7b00306

Sun, S., Zhang, G., Gauquelin, N., Chen, N., Zhou, J., Yang, S., et al. (2013). Singleatom catalysis using Pt/graphene achieved through atomic layer deposition. Sci. Rep. 3:1775. doi: 10.1038/srep01775

Tao, Y., Lin, Y., Huang, Z., Ren, J., and Qu, X. (2013). Incorporating graphene oxide and gold nanoclusters: a synergistic catalyst with surprisingly high peroxidase-like activity over a broad $\mathrm{pH}$ range and its application for cancer cell detection. Adv. Mater. 25, 2594-2599. doi: 10.1002/adma.2012 04419 
Wang, H., Li, P., Yu, D., Zhang, Y., Wang, Z., Liu, C., et al. (2018). Unraveling the enzymatic activity of oxygenated carbon nanotubes and their application in the treatment of bacterial infections. Nano Lett. 18, 3344-3351. doi: 10.1021/acs.nanolett.7b05095

Wang, H., Wan, K., and Shi, X. (2019). Recent advances in nanozyme research. Adv. Mater. 31:e1805368. doi: 10.1002/adma.201805368

Wang, Q., Zhang, X., Huang, L., Zhang, Z., and Dong, S. (2017). One-pot synthesis of $\mathrm{Fe} 3 \mathrm{O} 4$ nanoparticle loaded 3D porous Ggraphene nanocomposites with enhanced nanozyme activity for glucose detection. ACS Appl. Mater. Interfaces 9, 7465-7471. doi: 10.1021/acsami.6b16034

Wei, H., and Wang, E. (2013). Nanomaterials with enzyme-like characteristics (nanozymes): next-generation artificial enzymes. Chem. Soc. Rev. 42, 6060-6093. doi: 10.1039/c3cs35486e

Wu, J., Wang, X., Wang, Q., Lou, Z., Li, S., Zhu, Y., et al. (2019). Nanomaterials with enzyme-like characteristics (nanozymes): next-generation artificial enzymes (II). Chem. Soc. Rev. 48, 1004-1076. doi: 10.1039/C8CS00457A

Yang, Z., Zhou, X., Jin, Z., Liu, Z., Nie, H., Chen, X., et al. (2014). A facile and general approach for the direct fabrication of $3 \mathrm{D}$, vertically aligned carbon nanotube array/transition metal oxide composites as nonPt catalysts for oxygen reduction reactions. Adv. Mater. 26, 3156-3161. doi: 10.1002/adma.201305513

Zhang, B., Chen, Y., Li, J., Pippel, E., Yang, H., Gao, Z., et al. (2015). High efficiency $\mathrm{Cu}-\mathrm{ZnO}$ hydrogenation catalyst: the tailoring of $\mathrm{Cu}-\mathrm{ZnO}$ interface sites by molecular layer deposition. ACS Catal. 5, 5567-5573. doi: 10.1021 /acscatal.5b01266

Zhang, B., and Qin, Y. (2018). Interface tailoring of heterogeneous catalysts by atomic layer deposition. ACS Catal. 8, 10064-10081. doi: 10.1021/acscatal.8b02659
Zhang, J., Chen, C., Yan, W., Duan, F., Zhang, B., Gao, Z., et al. (2016). Ni nanoparticles supported on CNTs with excellent activity produced by atomic layer deposition for hydrogen generation from the hydrolysis of ammonia borane. Catal. Sci. Technol. 6, 2112-2119. doi: 10.1039/C5CY01497B

Zhang, J., Chen, W., Ge, H., Chen, C., Yan, W., Gao, Z., et al. (2018). Synergistic effects in atomic-layer-deposited PtCox/CNTs catalysts enhancing hydrolytic dehydrogenation of ammonia borane. Appl. Catal. B 235, 256-263. doi: 10.1016/j.apcatb.2018.04.070

Zhao, X., Cheng, K., Hao, J., and Liu, D. (2008). Preparation of peracetic acid from hydrogen peroxide, part II: Kinetics for spontaneous decomposition of peracetic acid in the liquid phase. J. Mol. Catal. A Chem. 284, 58-68. doi: 10.1016/j.molcata.2008.01.003

Zhu, J., Peng, X., Nie, W., Wang, Y., Gao, J., Wen, W., et al. (2019). Hollow copper sulfide nanocubes as multifunctional nanozymes for colorimetric detection of dopamine and electrochemical detection of glucose. Biosens. Bioelectron. 141:111450. doi: 10.1016/j.bios.2019.111450

Conflict of Interest: The authors declare that the research was conducted in the absence of any commercial or financial relationships that could be construed as a potential conflict of interest.

Copyright (c) 2020 Yang, Li, Qin, Zhang and Chen. This is an open-access article distributed under the terms of the Creative Commons Attribution License (CC BY). The use, distribution or reproduction in other forums is permitted, provided the original author(s) and the copyright owner(s) are credited and that the original publication in this journal is cited, in accordance with accepted academic practice. No use, distribution or reproduction is permitted which does not comply with these terms. 